\title{
Damage plasticity model for passively confined concrete
}

\author{
Ben-ben $\mathrm{Li}^{1}$, Hai-bei Xiong ${ }^{1}$, Jia-fei Jiang ${ }^{1, *}$ and Yang Zhan ${ }^{2}$ \\ ${ }^{1}$ Department of Disaster Mitigation for Structures, College of Civil Engineering, Tongji University, Shanghai 200092, China \\ ${ }^{2}$ School of Architecture Engineering, Nanjing Institute of Technology, Nanjing 211167, China.
}

\begin{abstract}
This paper presents a modified concrete damage plasticity model (CDPM) for passively confined concrete within the concrete damage plasticity theory frame in ABAQUS. The modified CDPM can be used to simulate concrete under non-uniform passive confinement, for example, Fiber-reinforced polymer (FRP)-confined square concrete columns. The modification of CDPM includes a flow rule and a strain hardening/softening criterion in which dilation angle and yield stress are important parameters. Based on the true-triaxial experiment results of passively confined concrete, the dilation angle and yield stress were determined considering different confinement stiffness and non-uniform confinement stiffness ratio. Finally, the modified CDPM were incorporated in the ABAQUS model. The prediction of the finite element model of FRP-confined square concrete columns shows good prediction accuracy.
\end{abstract}

\section{Introduction}

Fiber-reinforced polymer (FRP) has been widely used in retrofit of concrete columns. Since FRP is a linear elastic material, when it is used to wrap concrete columns, the confinement provided by FRP jacket is passive confinement. Passive confinement means the confinement is not a constant, but changes with the deformation of concrete. The confinement in circular sections is uniform, whereas, the confinement is non-uniform in many other situations, such as in square and rectangular sections, partially wrapped columns, and columns under eccentric loading. The constitutive model for passively confined concrete is the basic for modelling FRP-confined concrete columns with finite element method. The existing constitutive models mainly focus on concrete under uniform passive confinement $[1,2]$. For concrete under non-uniform passive confinement, the equivalent uniform confinement concept is adopted in the constitutive relationship [3, 4]. However, as reported by Zeng et al.[5], the prediction accuracy needs to be improved in simulation of columns under nonuniform passive confinement with constitutive model based on equivalent uniform concept. The constitutive model considering the influence of non-uniform confinement ratio is urgent to be established to give precise prediction of concrete columns under non-uniform passive confinement.

The constitutive model for non-uniformly passively confined concrete was established in this paper based on the concrete damage plasticity model (CDPM) frame in ABAQUS. First, the shear strength ratio in Lubliner and Lee yield criterion $[6,7]$ was determined based on the distribution characteristic of experiment data in stress space. Then, the yield stress was calculated according to the Lubliner and Lee yield criterion $[6,7]$. The relationship between yield stress and concrete strength, axial plastic strain, confinement stiffness, and non-uniform confinement stiffness ratio was established. Afterwards, the dilation angle was calculated according to the flow rule and the lateral strain-axial strain curve. The relationship between dilation angle and axial plastic strain, confinement stiffness and non-uniform confinement stiffness ratio was determined. Finally, the modified CDPM was incorporated with ABAQUS, and was used to simulate six groups of FRP-confined square concrete columns with different corner radius.

\section{Experimental database}

The constitutive model is established on the experiment data of true-triaxial compression experiment on passively confined concrete[8]. In the experiment, GFRP bars were used to generate passive confinement which was transferred to concrete cube by steel platen. Totally, 117 concrete cubes (Table 1) were casted, which were divided into 3 groups according to concrete strength $\left(f_{\mathrm{c} 0}=25.4 \mathrm{MPa}, 36 \mathrm{MPa}\right.$ and $44 \mathrm{MPa})$. Thirteen confinement conditions were designed for each group, considering lateral confinement stiffness $\rho$ (Eq. (1)) and non-uniform confinement stiffness ratio $\eta$ (Eq. (2)).

$$
\begin{gathered}
\rho_{1}=\frac{\Delta \sigma_{1}}{\Delta \varepsilon_{1} f_{\mathrm{c} 0}} ; \quad \rho_{2}=\frac{\Delta \sigma_{2}}{\Delta \varepsilon_{2} f_{\mathrm{c} 0}} \\
\eta=\frac{\min \left(\rho_{1}, \rho_{2}\right)}{\max \left(\rho_{1}, \rho_{2}\right)}
\end{gathered}
$$

where $\rho_{1}, \rho_{2}$ is lateral confinement stiffness in two lateral directions, respectively; $\sigma_{1}, \sigma_{2}$ is lateral confinement; $\varepsilon_{1}, \varepsilon_{2}$ is lateral strain ; $f_{\mathrm{c} 0}$ is unconfined concrete strength.

Table 1. Experimental database

\begin{tabular}{|c|c|c|c|c|c|c|}
\hline Spe. ID & $f_{\mathrm{c} 0}$ & $D_{1}$ & $D_{2}$ & $\rho_{1}$ & $\rho_{2}$ & $\eta$ \\
\hline N-A-20 & 20 & 0 & 8 & 0 & 20.8 & 0 \\
\hline N-B-20 & 20 & 0 & 10 & 0 & 27 & 0 \\
\hline N-C-20 & 20 & 0 & 14 & 0 & 40.8 & 0 \\
\hline N-D-20 & 20 & 0 & 16 & 0 & 42.2 & 0 \\
\hline N-A-30 & 36 & 0 & 8 & 0 & 15.4 & 0 \\
\hline
\end{tabular}

\footnotetext{
* Corresponding author: jfjiang@tongji.edu.cn
} 
Continued Table 1

\begin{tabular}{|c|c|c|c|c|c|c|}
\hline Spe. ID & $f_{\text {c0 }}$ & $D_{1}$ & $D_{2}$ & $\rho_{1}$ & $\rho_{2}$ & $\eta$ \\
\hline N-B-30 & 36 & 0 & 10 & 0 & 18.9 & 0 \\
\hline N-C-30 & 36 & 0 & 14 & 0 & 20.3 & 0 \\
\hline N-D-30 & 36 & 0 & 16 & 0 & 24.4 & 0 \\
\hline N-A-40 & 43 & 0 & 8 & 0 & 4.7 & 0 \\
\hline N-B-40 & 43 & 0 & 10 & 0 & 13.8 & 0 \\
\hline N-C-40 & 43 & 0 & 14 & 0 & 23.7 & 0 \\
\hline N-D-40 & 43 & 0 & 16 & 0 & 26.8 & 0 \\
\hline A-A-20 & 25.4 & 8 & 8 & 16.3 & 16.3 & 1 \\
\hline B-B-20 & 25.4 & 10 & 10 & 22.9 & 22.9 & 1 \\
\hline C-C-20 & 25.4 & 14 & 14 & 33.2 & 33.2 & 1 \\
\hline D-D-20 & 25.4 & 16 & 16 & 37.7 & 37.7 & 1 \\
\hline A-A-30 & 36 & 8 & 8 & 11.3 & 11.3 & 1 \\
\hline B-B-30 & 36 & 10 & 10 & 16.1 & 16.1 & 1 \\
\hline C-C-30 & 36 & 14 & 14 & 23.5 & 23.5 & 1 \\
\hline D-D-30 & 36 & 16 & 16 & 25.9 & 25.9 & 1 \\
\hline A-A-40 & 44 & 8 & 8 & 9.4 & 9.4 & 1 \\
\hline B-B-40 & 44 & 10 & 10 & 13.3 & 13.3 & 1 \\
\hline C-C-40 & 44 & 14 & 14 & 19.2 & 19.2 & 1 \\
\hline D-D-40 & 44 & 16 & 16 & 21.2 & 21.2 & 1 \\
\hline A-C-20 & 20 & 8 & 14 & 19.6 & 41.9 & 0.47 \\
\hline B-C-20 & 20 & 10 & 14 & 28.9 & 39.9 & 0.72 \\
\hline A-D-20 & 20 & 8 & 16 & 18.6 & 40.7 & 0.46 \\
\hline B-D-20 & 20 & 10 & 16 & 28.9 & 39.8 & 0.72 \\
\hline C-D-20 & 20 & 14 & 16 & 38.4 & 47.0 & 0.82 \\
\hline A-C-30 & 36 & 8 & 14 & 11.1 & 24.5 & 0.45 \\
\hline B-C-30 & 36 & 10 & 14 & 17.0 & 22.5 & 0.76 \\
\hline A-D-30 & 36 & 8 & 16 & 10.2 & 23.9 & 0.42 \\
\hline B-D-30 & 32 & 10 & 16 & 17.8 & 26.1 & 0.68 \\
\hline C-D-30 & 32 & 14 & 16 & 26.8 & 28.6 & 0.94 \\
\hline A-C-40 & 43 & 8 & 14 & 9.4 & 18.9 & 0.50 \\
\hline B-C-40 & 43 & 10 & 14 & 13.7 & 19.5 & 0.70 \\
\hline A-D-40 & 43 & 8 & 16 & 9.6 & 21.0 & 0.46 \\
\hline C-D & 44 & 14 & 16 & 19.6 & 20.9 & 0.94 \\
\hline
\end{tabular}

Note: $D_{1}$ and $D_{2}$ are diameters of GFRP bars in two lateral directions.

\section{Yield criterion}

The yield function $F$ of concrete damage plasticity model (CDPM) proposed by Lubliner et al.[6] and modified by Lee and Fenves[7] was adopted in this paper.

$$
F=\frac{\left(\bar{q}-3 A \bar{p}+B\left(\tilde{\varepsilon}^{p l}\right)\left\langle\bar{\sigma}_{\max }\right\rangle-C\left\langle-\bar{\sigma}_{\max }\right\rangle\right)}{1-A}-\bar{\sigma}_{c \mathrm{n}}\left(\tilde{\varepsilon}_{c}^{p l}\right)=0
$$

$$
\langle x\rangle=\frac{1}{2}(|x|+x)
$$

where $\bar{\sigma}_{i}=\sigma_{i} /\left(1-d_{\mathrm{c}}\right), \bar{q}, \bar{p}$ and $\bar{\sigma}_{c \mathrm{n}}$ are effective deviatoric stress, average stress and yield stress, respectively; $d_{\mathrm{c}}$ is damage parameter. For FRP-confined concrete, concrete is under triaxial compression. $\bar{\sigma}_{\max }<0$, and $\left\langle\bar{\sigma}_{\text {max }}\right\rangle=0,\left\langle-\bar{\sigma}_{\text {max }}\right\rangle=-\bar{\sigma}_{\text {max }}$, Eq.(3) is then simplified into Eq.(5).

$$
\begin{aligned}
& F=\frac{1}{1-A}\left(\bar{q}-3 A \bar{p}+C \bar{\sigma}_{\max }\right)-\bar{\sigma}_{c \mathrm{n}}\left(\tilde{\varepsilon}_{c}^{p l}\right)=0 \\
& \text { where } \quad A=\frac{f_{b 0} / f_{c 0}-1}{2 f_{b 0} / f_{c 0}-1} \\
& C=\frac{3(1-K)}{2 K-1}
\end{aligned}
$$

where $f_{\mathrm{b} 0}$ is concrete strength under equal biaxial compression; $f_{\mathrm{c} 0}$ is unconfined concrete strength; $K$ is shear strength ratio.

\subsection{Shear strength ratio}

Shear strength ratio is the ratio of deviatoric stress of concrete under equal biaxial compression $\left(\sigma_{1}=0\right.$, $\sigma_{2}=\sigma_{3}<0$ ) to triaxial compression where two lateral stresses are equal and larger than axial stress $\left(0>\sigma_{1}=\sigma_{2}>\sigma_{3}\right)$. The shear strength ratio $K$ is taken as 0.725 , which was first proposed by $\mathrm{Yu}$ et al.[2]. The distribution of stress point in deviatoric plane is shown in Fig.1. The Lode angle of the experimental data is between $56^{\circ}$ and $60^{\circ}$. As can be seen, $K=0.725$ can well simulate the distribution of stress point in this range.

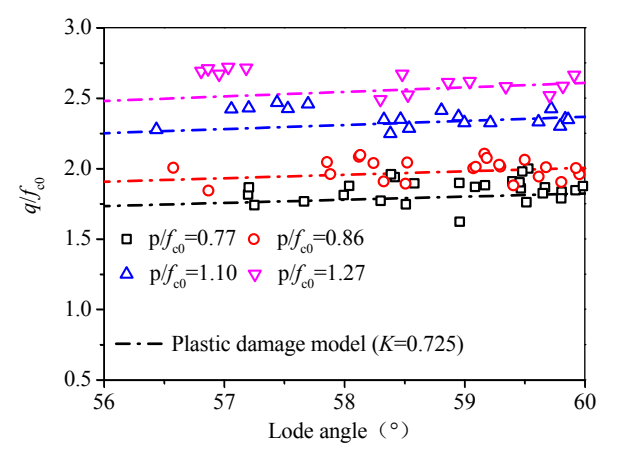

Fig. 1. Experimental and theoretical equivalent pressure

\subsection{Damage parameter}

For concrete with strain hardening, the damage parameter is defined as zero. For concrete with strain softening, the damage parameter is defined with Eq. (8).

$$
d_{c}=1-\frac{\sigma_{c}}{f_{c c}}
$$

Where $d_{\mathrm{c}}$ is compression damage parameter, $\sigma_{\mathrm{c}}$ is axial stress in strain softening phase, $f_{\mathrm{cc}}$ is the peak stress.

\section{3 yield stress}


According to Eq. (5), the yield stress can be determined as follows

$$
\bar{\sigma}_{c n}\left(\tilde{\varepsilon}_{c}^{p l}\right)=\frac{1}{1-A}\left(\overline{\mathrm{q}}-3 A \overline{\mathrm{p}}+C \bar{\sigma}_{\max }\right)
$$

The curve that yield stress varies with axial plastic strain is shown in Fig.2 and Fig.3. It is noted that in Fig.2 and Fig.3, nominal yield stress is the result of yield stress divided by concrete strengh. As can be seen in Fig.2, when concrete is under uniform passive confinement, the nominal yield stress increases with the increase of confinement stiffness. It is shown in Fig.3, For concrete with unidirectional passive $\operatorname{confinement}(\eta=0)$, the nominal yield stress exhibits strain softening. With the increase of non-uniform confinement stiffness ratio, the nomial yield stress changes from strain softening to strain hardening gradually. Eq. (10) was used to describe the relationship between nominal yield stress and axial plastic strain, confinement stiffness and non-uniform confinement stiffness ratio. The behavior of Eq. (10) is shown in Fig.2 and Fig.3, which shows good coincidence with the experimental results.

$$
\begin{aligned}
& \frac{\bar{\sigma}_{c \mathrm{n}}}{f_{c 0}}=a^{\prime}+\frac{b^{\prime} \varepsilon_{c}^{p}}{1+c^{\prime} \varepsilon_{c}^{p}}+d^{\prime} \varepsilon_{c}^{p} \\
& a^{\prime}=0.142 ; \quad b^{\prime}=8755 ; \quad c^{\prime}=9949 \\
& d^{\prime}=\frac{13.66(\eta-1)}{\eta+0.26}+\frac{-31.85+2.76 \rho_{\max }-0.023 \rho_{\max }{ }^{2}}{1+0.032 \rho_{\max }}
\end{aligned}
$$

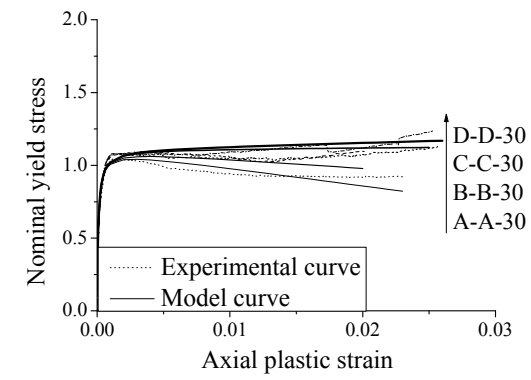

Fig. 2. Nominal yield stress of concrete under non-uniform passive confinement

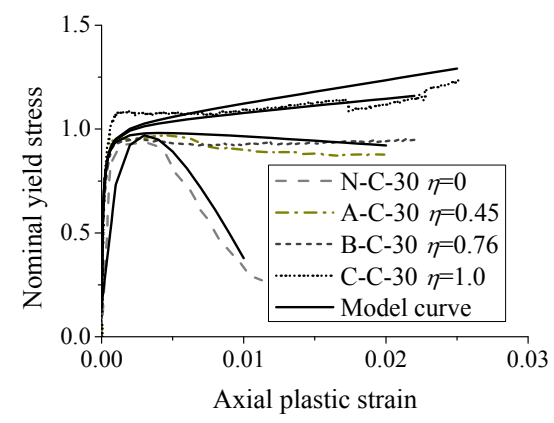

Fig. 3. Nominal yield stress of concrete under non-uniform passive confinement

\section{Dilation angle}

The flow rule of potential function of CDPM is described in hyperbolic function (Eq. (13)).

$G=\sqrt{\left(\left.\in \bar{\sigma}\right|_{0} \tan \psi\right)^{2}+\bar{q}^{2}}-\bar{p} \tan \psi$ where $\in$ referred to the eccentricity; $\left.\bar{\sigma}\right|_{0}$ referred to uniaxial tensile stress; $\psi$ referred to dilation angle.

According to the normality flow rule of plastic strain, the plastic strain of each direction can be determined by

$$
d \varepsilon_{i}^{p}=\lambda \frac{\partial G}{\partial \sigma_{i}}(i=1,2,3)
$$

The relationship between dilation angle and the axial strain increment can be obtained :

$$
\begin{gathered}
\tan \psi=\frac{\sqrt{3}}{2} \frac{d I_{1}^{\prime p}}{d \sqrt{J_{2}^{\prime}}} \\
d I_{1}^{\prime p}=d \varepsilon_{l 1}^{p}+d \varepsilon_{l 2}^{p}+d \varepsilon_{c}^{p}
\end{gathered}
$$

$d \sqrt{J_{2}^{\prime p}}=$

$$
\sqrt{\frac{1}{6}\left[\left(d \varepsilon_{l 1}^{p}-d \varepsilon_{l 2}^{p}\right)^{2}+\left(d \varepsilon_{l 2}^{p}-d \varepsilon_{c}^{p}\right)^{2}+\left(d \varepsilon_{l 1}^{p}-d \varepsilon_{c}^{p}\right)^{2}\right]}
$$

where $\varepsilon_{l 1}^{p}, \varepsilon_{l 2}^{p}, \varepsilon_{c}^{p}$ referred to lateral plastic strain in two directions and axial plastic strain, respectively.

The dilation angle of unidirectional passive confinement is shown in Fig. 4. For concrete under unidirectional passive confinement, the effective confinement is not formed. The dilation angle stays around $45^{\circ}$. Concrete keeps in dilation, and the stressstrain curve shows strain softening.

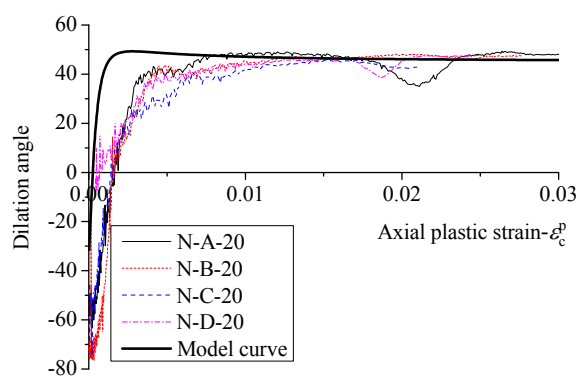

Fig. 4. Dilation angle of concrete under unidirectional passive confinement

The dilation angle of concrete under uniform passive confinement is shown in Fig.5. As shown in Fig.5, dilation angle increases first and then decreases gradually. Small dilation angle means concrete exhibits large compaction, rather than dilation. When the confinement ratio is larger, concrete is under more effective confinement and shows smaller dilation angle.

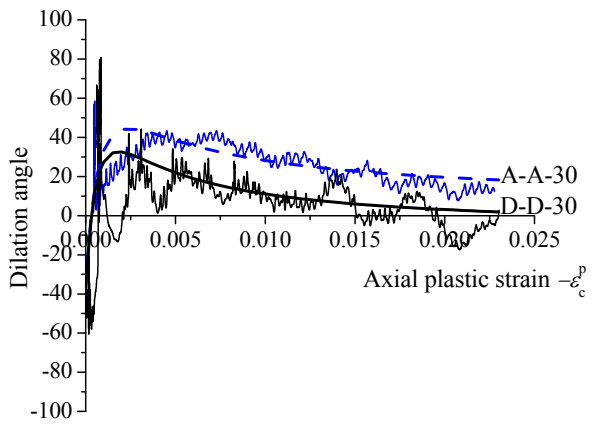

Fig. 5. Dilation angle of concrete under uniform passive confinement 
For concrete under non-uniform passive confinement (Fig.6), when the non-uniform confinement ratio is larger, the difference between confinements in two lateral directions is smaller, which leads to more uniform confinement field, more effective confinement for concrete and smaller dilation angle.

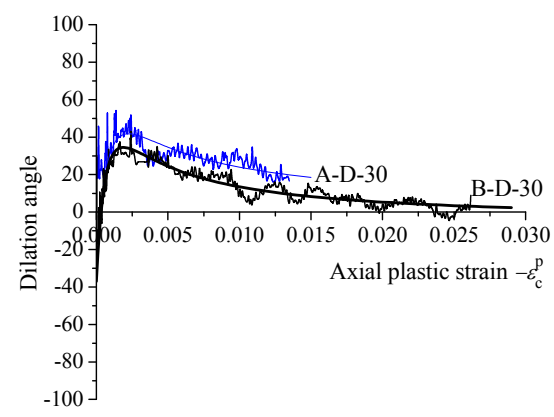

Fig. 6. Dilation angle of concrete under non-uniform passive confinement

Eq. (18) was used to describe the relationship between dilation angle and axial plastic strain. The result of function is shown in Fig.4, Fig.5 and Fig.6, which shows good coincidence.

$$
\begin{gathered}
\psi=\frac{\psi_{0}+\left(M_{0}+\lambda_{1} \psi_{0}\right)\left(\frac{\varepsilon_{c}^{p}}{0.01}\right)+\lambda_{2} \psi_{u}\left(\frac{\varepsilon_{c}^{p}}{0.01}\right)^{2}}{1+\lambda_{1}\left(\frac{\varepsilon_{c}^{p}}{0.01}\right)+\lambda_{2}\left(\frac{\varepsilon_{c}^{p}}{0.01}\right)^{2}} \\
\lambda_{1}=0.0011 \rho_{\eta}^{2}-0.0277 \rho_{\eta}+11.022 \\
\lambda_{2}=\frac{253.6+29.86 \rho_{\eta}+2.24 \rho_{\eta}{ }^{2}}{1+2.24 \rho_{\eta}} \\
\rho_{\eta}=\left(1.9 \eta-0.9 \eta^{2}\right) 25.77 f_{c 0}^{-0.55} \rho_{\max }{ }^{0.72}
\end{gathered}
$$

\section{Simulation of FRP-confined square columns}

The proposed concrete damage plasticity model, Eq. (10)-Eq. (12) for yield stress and Eq. (18)-Eq. (23) for dilation angle, was adopted to simulate concrete columns under non-uniform passive confinement in finite element software ABAQUS. The experimental results of Wang and $\mathrm{Wu}$ [9] were adopted. In their study, the specimens were $150 \mathrm{~mm} \times 150 \mathrm{~mm}$ concrete square columns with different corner radius $r(r=0,15 \mathrm{~mm}, 30 \mathrm{~mm}, 45 \mathrm{~mm}, 60 \mathrm{~mm}$ and $75 \mathrm{~mm}$ ). The concrete strength was $31.7 \mathrm{MPa}$, the elastic modulus, tensile strength and thickness of FRP were $219 \mathrm{GPa}, 4364 \mathrm{MPa}$ and $0.165 \mathrm{~mm}$, respectively.

In the finite element model, concrete was simulated with solid element C3D8R, FRP was simulated with membrane element M3D4R. They were tied together to ensure collaborative work. The lateral strain-axial stress curve and axial strain-axial stress curves are shown in Fig.7. The good agreement proves the feasibility of the proposed model.

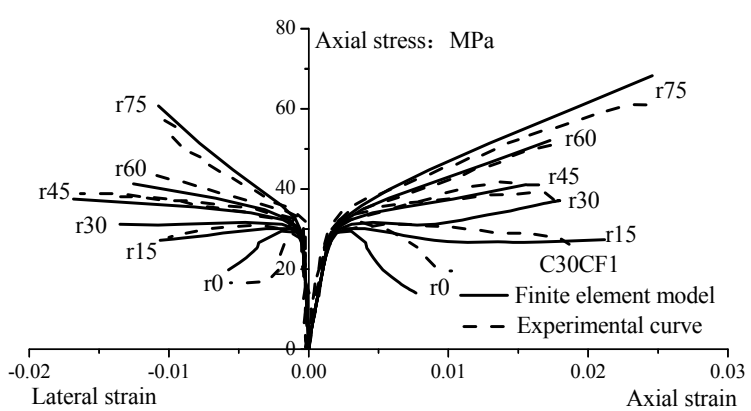

Fig. 7. Overall performance of the proposed model

\section{Conclusions}

A concrete damage plasticity model for passively confined concrete is presented in this paper. Based on the experimental results, the shear strength ratio, damage parameter, and yield stress in the yield criterion and dilation angle in flow rule were analysed and determined. The main findings of the paper are as follows.

1) The shear strength ratio of 0.725 can well describe the deviatoric stress distribution of non-uniformly passively confined concrete.

2) The yield stress of concrete under unidirectional passive confinement shows strain softening. With the increase of lateral confinement stiffness and non-uniform confinement stiffness ratio, yield stress curve gradually develops from strain softening to strain hardening.

3) For concrete under unidirectional passive confinement, the dilation angle stays stable around $45^{\circ}$. For concrete under uniform and non-uniform passive confinement, the dilation angle decreases with higher confinement stiffness and non-uniform confinement stiffness ratio.

4) The proposed model can well simulate the mechanical behaviour of FRP-confined square concrete columns with different corner radius.

The work described in this paper was fully supported by Open Fund of State Key Laboratory of High Performance Civil Engineering Material (Grant No. 2018CEM003) and the National Natural Science Foundation of China (Grant No. 51708259).

\section{References}

1. J. Jiang, Y. Wu, Int. J. Identification of material parameters for Drucker-Prager plasticity model for FRP confined circular concrete columns. Solids. Struct.49(3-4):445-56.( 2012)

2. T. Yu, J. Teng, Y. Wong, S. Dong, Finite element modeling of confined concrete-I: Drucker-Prager type plasticity model. Eng. Struct. 32(3):665-79. (2010)

3. T. Yu, J. Teng, Y. Wong, S. Dong, Finite element modeling of confined concrete-II: Plastic-damage model. Eng. Struct.32(3):680-91. (2010)

4. N. Hany, E. Hantouche, M. Harajli, Finite element modeling of FRP-confined concrete using modified concrete damaged plasticity. Eng. Struct.125:1-14. (2016) 
5. J. Zeng, Y. Guo, L. Li, W. Chen, Behavior and ThreeDimensional Finite Element Modeling of Circular Concrete Columns Partially Wrapped with FRP Strips. Polymers-Basel.10(3). (2018)

6. J. Lubliner, J. Oliver, S. Oller, E. Onate, A PlasticDamage Model for Concrete. Int. J. Solids Struct.25(3):299-326. (1989)

7. J. Lee, G. Fenves, Plastic-damage model for cyclic loading of concrete structures. J. Eng. Mech. 124(8):892-900. (1998)

8. J. Jiang, P. Xiao, B. Li, True-triaxial compressive behaviour of concrete under passive confinement. Constr. Build. Mater.156:584-98. (2017)

9. L. Wang, Y. Wu, Effect of corner radius on the performance of CFRP-confined square concrete columns: Test. Eng. Struct. 30(2):493-505. (2008) 